\title{
Investigation of the Effects of Electron Translational Nonequilibrium on Numerical Predictions of Hypersonic Flow Fields
}

\author{
Erin Farbar, ${ }^{*}$ and Iain D. Boyd ${ }^{\dagger}$ \\ Department of Aerospace Engineering, University of Michigan, Ann Arbor, Michigan, USA \\ Minkwan Kim ${ }^{\ddagger}$ \\ Department of Supersonic and Hypersonic Technology, German Aerospace Center (DLR), Köln, Germany \\ Alexandre Martin $\S$ \\ Department of Mechanical Engineering, University of Kentucky, Lexington, Kentucky, USA
}

\begin{abstract}
In the present study, flight regimes of hypersonic vehicles are identified in which the lack of thermal equilibrium between the vibrational-electronic and the electron translational energy modes plays an important role in the determination of the flow field character. The effect of the nonequilibrium of the electron translational and vibrational-electronic modes on the flow field parameters of interest such as plasma density, electron temperature, and radiative heat flux is quantified. Additionally, the importance of the selection of the controlling temperature when modeling the ionization source terms in the flow field equations is investigated. The RAM-C II and Stardust vehicles and their associated missions are used as test cases. At the flight conditions investigated in this study, it appears that significant differences in the prediction of electron number density and temperature exist mainly for the lower energy, RAM-C II flight conditions. At the higher energy Stardust flight conditions, the differences in both the electron properties and the predicted radiation spectra are generally small between the electron equilibrium and nonequilibrium simulation results. The results of this study indicate that the selection of controlling temperature is important when modeling the associative ionization and reverse dissociative recombination reactions at these flight conditions.
\end{abstract}

\section{Nomenclature}

$\mathrm{C}_{V, e} \quad$ electron specific heat at constant volume, $\mathrm{J} / \mathrm{kg} / \mathrm{K}$

$\mathrm{e}_{e} \quad$ electron energy, $\mathrm{J} / \mathrm{kg}$

$\mathrm{e}_{e} \quad$ modified electron energy, $\mathrm{J} / \mathrm{kg}$

$\mathrm{E}_{e} \quad$ electron energy, $\mathrm{J} / \mathrm{m}^{3}$

$\mathrm{E}_{a} \quad$ threshold energy for chemical reaction, $\mathrm{J}$

$\mathrm{J}_{e} \quad$ electron mass diffusion flux, $\mathrm{kg} / \mathrm{m}^{2} / \mathrm{s}$

$\mathrm{k} \quad$ Boltzmann constant, $\mathrm{J} / \mathrm{K}$

$\mathrm{m}_{e} \quad$ mass of an electron, $\mathrm{kg}$

$\mathrm{n}_{e} \quad$ electron number density, $\mathrm{m}^{-3}$

$\mathrm{p}_{e} \quad$ electron partial pressure, $\mathrm{Pa}$

$\mathrm{q}_{e} \quad$ electron heat flux, $\mathrm{J} / \mathrm{m}^{2} / \mathrm{s}$

$\mathrm{T}_{c} \quad$ controlling temperature for chemical reaction, $\mathrm{K}$

$\mathrm{T}_{e} \quad$ electron translational temperature, $\mathrm{K}$

\footnotetext{
*Postdoctoral Research Fellow, Member AIAA. Email: efarbar@umich.edu

$\dagger$ James E. Knott Professor of Engineering, Fellow AIAA.

${ }^{\ddagger}$ Research Scientist, Member AIAA.

$\S$ Professor, Member AIAA.
} 


$\begin{array}{ll}\mathrm{T}_{t r} & \text { translational and rotational temperature, } \mathrm{K} \\ \mathrm{T}_{v} & \text { vibrational temperature, } \mathrm{K} \\ \mathrm{T}_{v e} & \text { vibrational-electronic temperature, } \mathrm{K} \\ \mathrm{u}, \mathrm{v}, \mathrm{w} & \text { flow velocity components, } \mathrm{m} / \mathrm{s} \\ \kappa & \text { reaction rate coefficient, } \mathrm{m}^{3} / \text { particle } / \mathrm{s} \\ \rho_{e} & \text { electron density, } \mathrm{kg} / \mathrm{m}^{3} \\ \rho_{s} & \text { density of species } \mathrm{s}, \mathrm{kg} / \mathrm{m}^{3} \\ \rho & \text { flow density, } \mathrm{kg} / \mathrm{m}^{3} \\ \tau_{e} & \text { electron viscous stress, } \mathrm{Pa}\end{array}$

\section{Introduction}

Recently, there has been increased interest both in the development of hypersonic cruise vehicles on the part of USAF, as well as in the development of a next-generation reentry vehicle to replace the Space Shuttle on the part of NASA. The design of such vehicles relies heavily on computational tools to predict the flow field characteristics at various points along the flight or reentry trajectory. The numerical prediction of the flow field about a hypersonic vehicle flying in the atmosphere is a complicated task that requires solving the Navier-Stokes equations while accounting for the presence of multiple species, thermal and chemical nonequilibrium, and in some cases a simultaneous, coupled calculation of flow field radiation and vehicle surface ablation. If descriptions of the onset and duration of interference with radio-frequency communication to the vehicle are needed, an important consideration for the design of a future hypersonic cruise vehicle, then the accurate prediction of electron properties (density, temperature) is required.

In this work, the focus is on the modeling of the electron translational energy mode using Computational Fluid Dynamics (CFD). The degree of nonequilibrium between the electron translational and the vibrationalelectronic energy modes is investigated at a flight condition that is realistic for a future hypersonic cruise vehicle, as well as at higher energy, reentry flight condition. The sensitivity of the flow field predictions to the choice of controlling temperature for the ionization reactions is investigated. The importance of including at least an eleven species chemistry model and modeling the catalycity of the vehicle surface to ion recombination is demonstrated. As adding an electron translational energy equation to the Navier-Stokes system of equations adds complexity and computational cost to the solution process, it is important to know when it can be neglected from the analysis. Thus, the primary goal of this study is to provide guidelines for when a separate electron translational energy mode should be accounted for during the simulation of hypersonic flow fields. The RAM-C and Stardust flights are chosen as test cases because measurements of electron number density, electron translational temperature and radiation spectra were made during the reentry of those vehicles. Additionally, these missions span a wide range of flight energies, with RAM-C II reentering from low Earth orbit at approximately $7.7 \mathrm{~km} / \mathrm{s}$, and Stardust performing a direct entry from an interplanetary trajectory at $12.6 \mathrm{~km} / \mathrm{s}$.

The paper is organized as follows. First, the various flow field conditions examined in this work are presented. Details are provided about the numerical methods used, and specific attention is paid to the implementation of the electron translational energy equation, the method of simulating the effects of finite rate chemistry, and the method used to obtain predictions of radiation spectra from the simulation results for the Stardust reentry. Flow field results are then presented for both the Stardust and RAM-C II vehicles, obtained with and without the use of a separate electron translational energy equation. Next, results are presented to illustrate the sensitivity of the chemistry modeling to the selection of controlling temperature. The results of the study are then summarized and conclusions are presented.

\section{Flow Conditions}

\section{II.A. RAM-C II}

The Radio Attenuation Measurement (RAM) program was a series of hypersonic experiments performed in the 1960's to study communications blackout. From all the flights performed, the RAM-C II flight is the most useful for numerical purposes due to the large amount of data collected during the reentry. During the flight, measurements were taken of the maximum electron number density normal to the surface at 
four different locations along the body using reflectometers. Additionally, a rake of electrostatic probes measured the variation of electron number density normal to the vehicle, at a location close to the rear of the spacecraft. ${ }^{1,2}$ The flight conditions simulated in this study are given in Table 1 . The vehicle surface is assumed to be at a constant temperature of $1200 \mathrm{~K}$ in all simulations. The geometry of the vehicle is shown in Figure 1(a), and the mesh used to obtain the solution at the $61 \mathrm{~km}$ trajectory point is given in Figure 1(b).

Table 1: Free stream conditions for the RAM-C II simulations.

\begin{tabular}{lccccc}
\hline \hline Altitude, $\mathrm{km}$ & Velocity, m/s & Mach No. & Density, $\mathrm{kg} / \mathrm{m}^{3}$ & Temperature, K & Knudsen No. \\
\hline 61 & 7651 & 24 & $2.73 \times 10^{-4}$ & 244 & $1.5 \times 10^{-3}$ \\
71 & 7661 & 26 & $7.20 \times 10^{-5}$ & 217 & $5.7 \times 10^{-3}$ \\
\hline
\end{tabular}



(a) Vehicle geometry.



(b) Mesh for the $61 \mathrm{~km}$ simulation.

Figure 1: RAM-C II.

Because experimental measurements of plasma density obtained during hypersonic flight are rare, multiple $\mathrm{CFD}^{3-5}$ and direct simulation Monte Carlo (DSMC) ${ }^{6,7}$ numerical studies have utilized the RAM-C II data for code validation. This study is unique because to the authors' knowledge, a comparison of plasma density predictions obtained from a CFD code that includes an eleven species air model to the measured data has not been previously published. Additionally, an assessment has not yet been made of the need to model a separate electron translational energy mode using continuum simulation techniques at this type of hypersonic flight condition.

\section{II.B. Stardust}

The Stardust payload was launched in 1999 on a mission to collect samples from the interstellar dust and the tail of the Comet Wild-2 and return them to Earth. It reentered and landed in the Utah desert in January of 2006. The Stardust spacecraft then continued its travel through the solar system, on a mission to image Comet Tempel-1. It was decommissioned after completing that final mission in March 2011. The original Stardust mission represents the first ever return of a sample from a comet; a significant milestone in the human exploration of space. With its entry velocity of $12.6 \mathrm{~km} / \mathrm{s}$, the capsule was also the fastest man-made object ever to enter the Earth's atmosphere, providing a unique test case to evaluate predictions from numerical simulations. Radiation emitted from the shock-heated air during the entry was measured at altitudes between $82 \mathrm{~km}$ and $69 \mathrm{~km}$ by a number of different instruments onboard a remotely located aircraft. The radiation spectra measured using the Echelle spectrograph ${ }^{8}$ is used to provide an assessment of the numerical results presented in this work. The flight conditions simulated in this study are given in Table 2. The vehicle surface was assumed to have a temperature of $2000 \mathrm{~K}$ at the $81 \mathrm{~km}$ trajectory point, and $3244 \mathrm{~K}$ at the $71 \mathrm{~km}$ trajectory point. The geometry of the vehicle is given in Figure 2(a), and the mesh used to obtain the solution at the $81 \mathrm{~km}$ trajectory point is given in Figure 2(b).

Because experimental data obtained at very high energy reentry conditions, such as those of the Stardust capsule, are rare, many numerical studies of the Stardust flow field at various altitudes have been performed using both continuum $\mathrm{CFD}^{9-14}$ and noncontinuum $\mathrm{DSMC}^{9,11,12,15}$ simulation techniques. Again, this study 
Table 2: Free stream conditions for the Stardust simulations.

\begin{tabular}{lccccc}
\hline \hline Altitude, $\mathrm{km}$ & Velocity, m/s & Mach No. & Density, $\mathrm{kg} / \mathrm{m}^{3}$ & Temperature, K & Knudsen No. \\
\hline 71 & 12063 & 40 & $5.55 \times 10^{-5}$ & 222 & $1.4 \times 10^{-3}$ \\
81 & 12385 & 42 & $1.27 \times 10^{-5}$ & 218 & $6.4 \times 10^{-3}$ \\
\hline
\end{tabular}



(a) Capsule geometry. ${ }^{9}$



(b) Forebody mesh for the $81 \mathrm{~km}$ simulation.

Figure 2: Stardust.

is unique, as a comparison of radiation spectra obtained from a CFD code that treats the electron translational energy mode separately to the measured data has not been previously published. Additionally, an assessment has not yet been made of the need to model a separate electron translational energy mode using continuum simulation techniques at this type of high-energy flight condition.

\section{Numerical method}

The Navier-Stokes equations are solved using an existing CFD code called LeMANS, which is developed at the University of Michigan. ${ }^{5,16}$ The finite-volume method is used to solve the set of differential equations, using a modified Steger-Warming Flux Vector Splitting approach which has low dissipation and is appropriate to calculate boundary layers. A point or line implicit method is used to perform the time integration. It is assumed that the translational and rotational energy modes can be described by a single temperature. The viscous stresses are modeled assuming a Newtonian fluid and Stokes' hypothesis, and the species mass diffusion fluxes are modeled using a modified version of Fick's law. Mixture transport properties are calculated using Gupta's mixing rules with species viscosities and thermal conductivities calculated using collision cross section data. Heat fluxes are modeling according to Fourier's law for all temperatures. An eleven species air finite rate chemistry model $\left(\mathrm{N}, \mathrm{O}, \mathrm{N}_{2}, \mathrm{O}_{2}, \mathrm{NO}, \mathrm{N}^{+}, \mathrm{O}^{+}, \mathrm{N}_{2}^{+}, \mathrm{O}_{2}^{+}, \mathrm{NO}^{+}\right.$and e) is used for all simulations unless noted otherwise, using the forward reaction rates given in Refs. 17 and 18. The reverse reaction rates are calculated using a curve-fit to tabulated values of the equilibrium constant for each reaction. ${ }^{18}$ The surface of the vehicles are modeled using both a noncatalytic boundary condition, and one that models the complete catalycity of the surface to ion recombination. 


\section{III.A. Modeling the Electron Translational Energy Mode}

Thermal nonequilibrium is accounted for with two different approaches. In the first approach, the electron translational temperature is assumed to be equal to the vibrational-electronic temperature, and only the latter is solved for using a conservation equation for the vibrational, electronic and electron translational energy. This is the most common approach in the hypersonic CFD community. In the second approach, a separate electron translational energy equation, given below, is solved to obtain an independent electron translational temperature.

$$
\frac{\partial E_{e}}{\partial t}+\frac{\partial}{\partial x^{j}}\left(E_{e} u^{j}\right)-\frac{\partial}{\partial x^{j}}\left(-q_{e}^{j}+\tau_{e}^{i j} u^{i}-J_{e}^{j} e_{e}\right)=S_{e}
$$

This equation was first suggested by Lee. ${ }^{19}$ The electron translational energy per unit volume, $E_{e}=\rho_{e} e_{e}$, is defined as

$$
E_{e}=\rho_{e} C_{V, e} T_{e}+\frac{1}{2} \rho_{e}\left(u^{2}+v^{2}+w^{2}\right),
$$

where $C_{V, e}=3 / 2\left(k / m_{e}\right)$.

The source term on the right hand side is given as follows.

$$
S_{e}=S_{\text {trans-e }}+S_{\text {inelastic }, e}+S_{\text {chemical }, e}+S_{\text {pressure }, e}
$$

Here $S_{\text {trans-e }}$ models the energy transfer between the flow translational and electron translational energy modes, $S_{\text {inelastic,e }}$ models the energy transfer between electrons and the vibrational-electronic energy mode and the rotational energy mode of molecules, and $S_{\text {chemical,e }}$ is the energy gained or lost by electrons during chemical reactions. The last term, $S_{\text {pressure,e }}=-p_{e} \nabla \cdot \vec{u}$, is an approximation to the energy gained by electrons as they travel through the electric field set up by the presence of both the ions and the electrons in the flow field. In the ambipolar diffusion approximation, this electric field is proportional to the gradient of the electron pressure. These terms are described in much more detail in Ref. 14.

Additionally, the electron energy per unit volume, $E_{e}=\rho_{e} e_{e}$ is modified and expressed as follows:

$$
E_{e}=\rho e_{e}^{\prime}
$$

where $e^{\prime}$ is the modified energy per unit mass, $e_{e}^{\prime}=\frac{\rho_{e}}{\rho} e_{e} \cdot{ }^{14}$ This step is taken to ensure that the derivative of the electron energy for species other than electrons, $\frac{\partial E_{e}}{\partial \rho_{s}}$, is not zero, as this would cause the Jacobian matrix to become singular.

\section{III.B. Chemistry Modeling}

The chemical reaction rates are functions of different mode temperatures; in principal, this functional dependence is determined by the details of the reaction mechanics. A controlling temperature, $T_{c}$, is used to evaluate the reaction rate coefficients, $\kappa=A T_{c}^{\eta} e^{-\frac{E_{a}}{k T_{c}}}$, in each cell and at each iteration of the simulation. When vibrational-electronic-electron translational equilibrium is considered, $\mathrm{T}_{e}$ is equal to $\mathrm{T}_{v}$ and the controlling temperature for each reaction is modeled as follows:

$$
T_{c}=T_{t r}^{a} T_{v e}^{b}
$$

where the parameters $\mathrm{a}$ and $\mathrm{b}$ can be adjusted to place a greater importance on either the translationalrotational temperature or the vibrational-electronic-electron translational temperature. When a separate electron translational energy equation is solved, Equation 5 is modified as given below.

$$
T_{c}=T_{t r}^{a} T_{v}^{b} T_{e}^{c}
$$

The baseline values of the parameters $\mathrm{a}, \mathrm{b}$ and $\mathrm{c}$ used in the electron nonequilibrium simulations are given in Table 3 for both the forward and backward rates of each type of reaction mechanism. There is some ambiguity in the choice of controlling temperature for most types of reactions. As an example, for associative ionization reactions such as $N+O \leftrightarrow N O^{+}+e$, the controlling temperature is currently set completely by the flow translational-rotational temperature. However, a recent DSMC study ${ }^{20}{ }^{\text {suggests that the rate of }}$ this reaction could be strongly affected by the electronic energy of the colliding atoms. 
Table 3: Parameters used to define the controlling temperature for various reaction types.

\begin{tabular}{lcccccc}
\hline \hline \multirow{2}{*}{ Reaction } & \multicolumn{3}{c}{ Forward } & \multicolumn{3}{c}{ Backward } \\
& $\mathrm{a}$ & $\mathrm{b}$ & $\mathrm{c}$ & $\mathrm{a}$ & $\mathrm{b}$ & $\mathrm{c}$ \\
\hline Dissociation & 0.67 & 0.33 & 0.0 & 1.0 & 0.0 & 0.0 \\
Neutral exchange & 1.0 & 0.0 & 0.0 & 1.0 & 0.0 & 0.0 \\
Associative ionization & 1.0 & 0.0 & 0.0 & 0.0 & 0.5 & 0.5 \\
Charge exchange & 1.0 & 0.0 & 0.0 & 1.0 & 0.0 & 0.0 \\
Electron impact dissociation & 0.0 & 0.5 & 0.5 & 0.5 & 0.0 & 0.5 \\
Electron impact ionization & 0.0 & 0.0 & 1.0 & 0.0 & 0.0 & 1.0 \\
\hline
\end{tabular}

In this study, the controlling temperature for reactions involving electrons and electronically excited particles such as associative ionization (AI) and the reverse reaction, dissociative recombination (DR), charge exchange reactions, and electron impact ionization and electron impact dissociation is varied systematically while considering the mechanics of the reactions. For example, the forward and reverse reaction rates for the electron impact ionization mechanism were originally determined solely by the electron translational temperature. However, a recent study shows that in near-continuum hypersonic flow fields, the use of electron impact ionization cross section data that is a function of the electronic state of the colliding atoms has a non-negligible effect on the predicted flow field properties. ${ }^{21}$ So, the rate for this reaction is modified such that it is computed using both the vibrational-electronic temperature and the electron translational temperature. The modified parameters for this and the other reaction mechanisms are given in Table 4. The effect of these changes on the predicted electron properties is investigated for both test cases. This procedure will not identify the correct parameters to use in Equation 6, if such parameters even exist, but it will identify reactions for which further investigation into a means by which to determine these parameters is necessary.

Table 4: Modified parameters used to define the controlling temperature for various reaction types.

\begin{tabular}{lcccccc}
\hline \hline \multirow{2}{*}{ Reaction } & \multicolumn{3}{c}{ Forward } & \multicolumn{3}{c}{ Backward } \\
& $\mathrm{a}$ & $\mathrm{b}$ & $\mathrm{c}$ & $\mathrm{a}$ & $\mathrm{b}$ & $\mathrm{c}$ \\
\hline Neutral exchange & 0.5 & 0.5 & 0.0 & 0.5 & 0.5 & 0.0 \\
Associative ionization - 1 & 0.5 & 0.5 & 0.0 & 0.0 & 0.5 & 0.5 \\
Associative ionization - 2 & 0.5 & 0.0 & 0.5 & 0.0 & 0.5 & 0.5 \\
Associative ionization - 3 & 0.0 & 0.0 & 1.0 & 0.0 & 0.5 & 0.5 \\
Associative ionization - 4 & 1.0 & 0.0 & 0.0 & 0.5 & 0.0 & 0.5 \\
Charge exchange & 0.5 & 0.5 & 0.0 & 0.5 & 0.5 & 0.0 \\
Electron impact dissociation & 0.0 & 0.0 & 1.0 & 0.5 & 0.0 & 0.5 \\
Electron impact ionization & 0.0 & 0.5 & 0.5 & 0.0 & 0.0 & 1.0 \\
\hline
\end{tabular}

\section{III.C. Radiation Model}

Line-of-sight radiation spectra are obtained from the converged flow field results for the Stardust case by postprocessing the data using the NASA NEQAIR nonequilibrium radiation code. ${ }^{22}$ NEQAIR takes as inputs the species number densities, temperatures of the translational, rotational and vibrational modes, and the electron translational temperature. It allows the population of excited states to be computed using both the equilibrium assumption (Boltzmann distribution), and well as the quasi-steady-state (QSS) assumption. In this work, they are populated using the QSS assumption. Data are extracted from the flow field solutions along lines of constant radial location at $\mathrm{r}=0.0 \mathrm{~m}, \mathrm{r}=0.2 \mathrm{~m}, \mathrm{r}=0.3 \mathrm{~m}$, and $\mathrm{r}=0.42 \mathrm{~m}$, and spectra are computed for each. The spectral results are then averaged considering the area of the flow field visible to 
the Echelle instrument to obtain the spectra that are presented in the following sections. Further details regarding the use of NEQAIR in conjunction with flow field results in this type of situation are found in Ref. 12.

\section{Results}

\section{IV.A. RAM-C II}

Contours of the electron number density at an altitude of $61 \mathrm{~km}$ are shown in Figure 3, in order to illustrate the general character of the flow field. These results are obtained from the simulations computed assuming electron nonequilibrium $\left(\mathrm{T}_{e} \neq \mathrm{T}_{v}\right)$. This figure shows that the peak electron number density occurs in the region of the stagnation streamline in front of the nose of the vehicle, with a value of $1.9 \times 10^{20} \mathrm{~m}^{-3}$.



Figure 3: Contours of electron number density around the RAM-C II vehicle at an altitude of $61 \mathrm{~km}$.

Figure 4(a) shows the maximum predicted electron number density normal to the vehicle surface as a function of position along the vehicle at the $61 \mathrm{~km}$ flight condition. Also shown on this figure is data from both the reflectometers and the electrostatic probes that were employed on the vehicle. Activating ion recombination at the vehicle surface reduces the peak electron density at most axial locations, and increases the level of agreement between the simulation results and the experimental data. Solving the electron energy equation rather than assuming vibrational-electronic-electron translational equilibrium has a significant effect on the magnitude of electron number density at the $61 \mathrm{~km}$ condition. Finally, reducing the complexity of the chemistry model to include only the $\mathrm{NO}^{+}$ion and the first associative ionization mechanism, $N+O \rightarrow N^{+}+e$ (results labeled "7 species chemistry" in Figure 4(a)), further increases the level of agreement between the simulation results and the data at the $61 \mathrm{~km}$ flight condition. The latter is a counter-intuitive result, and suggests that the modeling of physical phenomena needs to be improved in order to reproduce the experimental data.

Similar trends are seen in Figure 4(b), which shows the maximum electron number density at the $71 \mathrm{~km}$ altitude, as well as the experimental data at that flight condition. Again, activating ion recombination at the vehicle surface increases the level of agreement between the simulation results and the experimental data. However, allowing for electron nonequilibrium has a much less significant effect on the predicted maximum electron number density at this flight condition. This may be because the electron impact ionization reactions, the rates of which are determined by the electron translational temperature, produce a larger portion of the ionization events at the more dense $61 \mathrm{~km}$ flight condition than at the $71 \mathrm{~km}$ flight condition. In this case, 
changes to the electron temperature model would be expected to have a larger effect on the predicted electron number density at the $61 \mathrm{~km}$ condition than at the $71 \mathrm{~km}$ condition. In general, the agreement between the simulation results and the flight data is better at the $71 \mathrm{~km}$ altitude.

During the reentry of RAM-C II, measurements of the electron number density were made using a rake of electrostatic probes located near the rear of the vehicle at approximately $\mathrm{x}=1.2 \mathrm{~m}$. Figures $5(\mathrm{a})$ and $5(\mathrm{~b})$ show a comparison of the data from those measurements at both the $61 \mathrm{~km}$ and $71 \mathrm{~km}$ flight conditions with the results of the simulations. At both flight conditions, activating ion recombination at the vehicle surface significantly increases the level of agreement between the simulation results and the experimental data. Additionally, accounting for electron translational nonequilibrium further improves the level of agreement between the experimental data and the simulation results in the region less than $0.03 \mathrm{~m}$ away from the vehicle surface. At the $61 \mathrm{~km}$ flight condition, the deficiency of the seven species chemistry model is clear, as the results from that simulation under-predict the experimental measurements.

The importance of accounting for electron translational nonequilibrium when performing these calculations is further illustrated by comparing flow field properties along the stagnation streamline in front of the blunt nose of the vehicle. Figure 6 shows a comparison of the temperatures along the stagnation streamline at both the $61 \mathrm{~km}$ and $71 \mathrm{~km}$ flight conditions. This figure illustrates that failing to account for electron translational nonequilibrium when simulating this type of flight condition results in an under-prediction of the translational temperature, and an over-prediction of the vibrational temperature. Figure 7 shows a comparison of the electron number density along the stagnation streamline at both the $61 \mathrm{~km}$ and $71 \mathrm{~km}$ flight conditions. Allowing for electron translational nonequilibrium in the simulation results in a decrease in the predicted peak degree of ionization along the stagnation streamline by as much as a factor of two in some locations downstream of the shock, and a factor of ten in the boundary layer at the $71 \mathrm{~km}$ flight condition.

The magnitude of the surface heat flux did not change appreciably at either flight condition when the electron translational energy equation was included in the simulations and surface ion recombination was implemented. This is not surprising, since the specified wall temperature for the electron translational mode is the same as that of vibrational energy mode, and the contribution to the total heat flux from diffusion of ion and electron species at the wall is a small fraction of the total value. 




(a) $61 \mathrm{~km}$ flight condition.



(b) $71 \mathrm{~km}$ flight condition.

Figure 4: Maximum electron number density normal to the RAM-C II vehicle surface at the both flight conditions.



(a) $61 \mathrm{~km}$ flight condition.



(b) $71 \mathrm{~km}$ flight condition.

Figure 5: Electron number density normal to the RAM-C II vehicle surface at the location of the electrostatic probe rake for the each flight condition. 




(a) $61 \mathrm{~km}$ flight condition.



(b) $71 \mathrm{~km}$ flight condition.

Figure 6: Temperatures computed along the stagnation streamline for RAM-C II at both flight conditions.



(a) $61 \mathrm{~km}$ flight condition.



(b) $71 \mathrm{~km}$ flight condition.

Figure 7: Electron number density computed along the stagnation streamline for RAM-C II at both flight conditions. 


\section{IV.B. Stardust}

Contours of the electron number density at the $81 \mathrm{~km}$ flight condition are shown in Figure 8 . These results are obtained from the simulations computed assuming electron nonequilibrium $\left(\mathrm{T}_{e} \neq \mathrm{T}_{v}\right)$. Due to the blunted shape of the capsule, the peak electron density occurs in the shoulder region, rather than at the stagnation point as is typically seen with blunted-cone type geometries, such as RAM-C II. The peak electron density is approximately $7.0 \times 10^{19} \mathrm{~m}^{-3}$.



Figure 8: Contours of electron number density around the Stardust capsule at an altitude of $81 \mathrm{~km}$.

Figure 9 shows the predicted translational, vibrational, and electron translational temperatures along the stagnation streamline for both flight conditions, from both the electron thermal equilibrium and nonequilibrium simulations. In the case of the simulation employing electron thermal equilibrium, the electron translational temperature is given by the vibrational temperature, as the two modes are assumed to be in equilibrium. There is a significant difference between the predicted electron temperature in the two simulations, with the nonequilibrium results showing a flatter electron temperature profile, in strong nonequilibrium with the rest of the modes upstream of the shock.

Figure 10 shows the predicted electron number densities along the stagnation streamline for both flight conditions, again for simulations computed with and without the assumption of electron thermal equilibrium. At the $71 \mathrm{~km}$ altitude flight condition, the simulation employing the electron equilibrium assumption overpredicts the electron number density by a factor of approximately five at the start of the shock layer and under-predicts it by approximately $60 \%$ near the surface of the vehicle. At the $81 \mathrm{~km}$ altitude flight condition, the simulation employing the electron equilibrium assumption under-predicts the electron number density by approximately $60 \%$ near the surface of the vehicle, and slightly over-predicts it in the shock layer. 


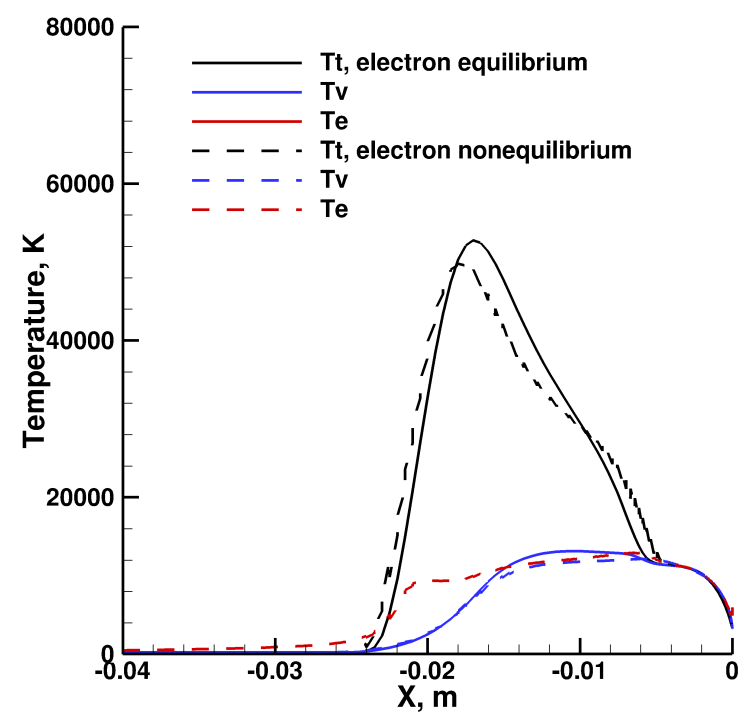

(a) $71 \mathrm{~km}$ flight condition.

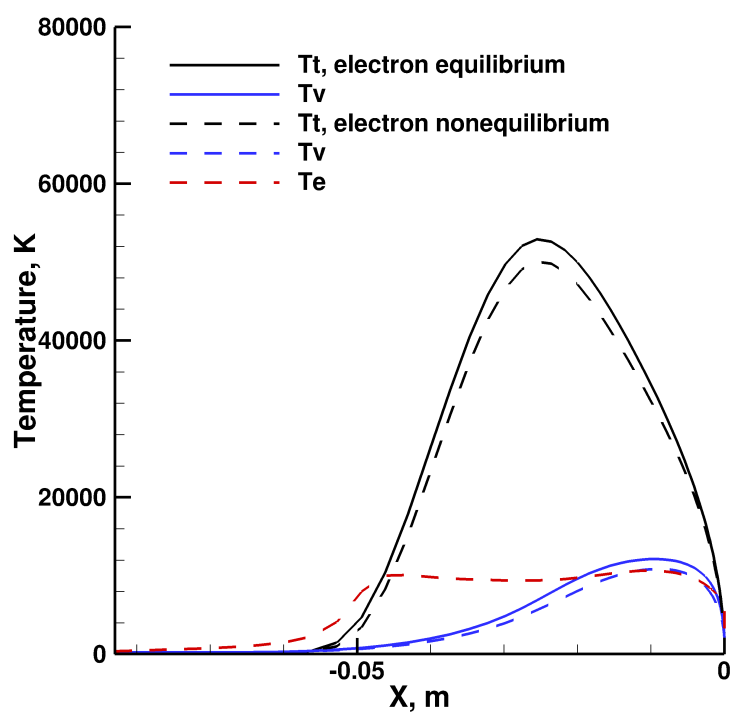

(b) $81 \mathrm{~km}$ flight condition.

Figure 9: Temperatures computed along the stagnation streamline for Stardust at both flight conditions.

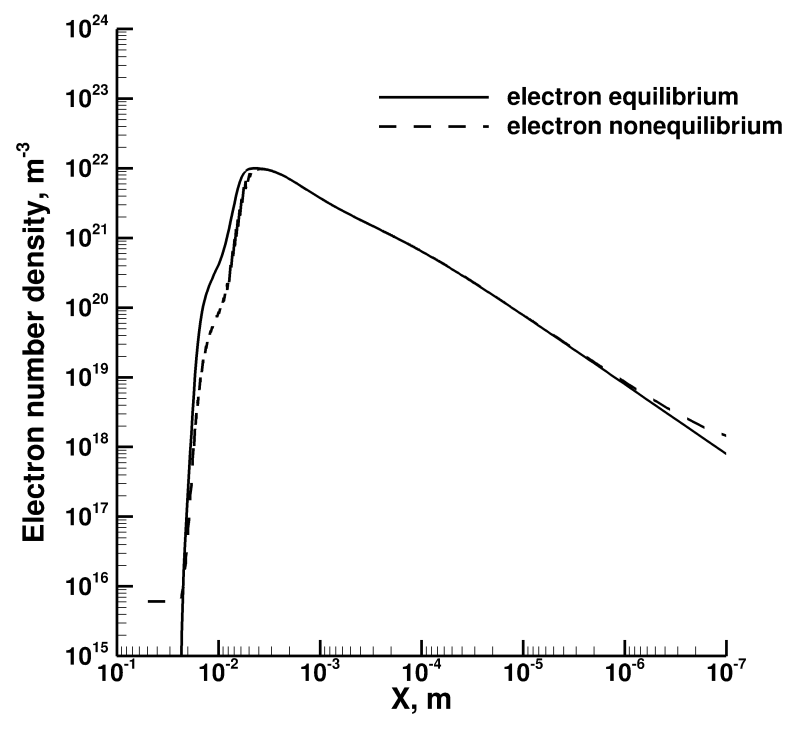

(a) $71 \mathrm{~km}$ flight condition.

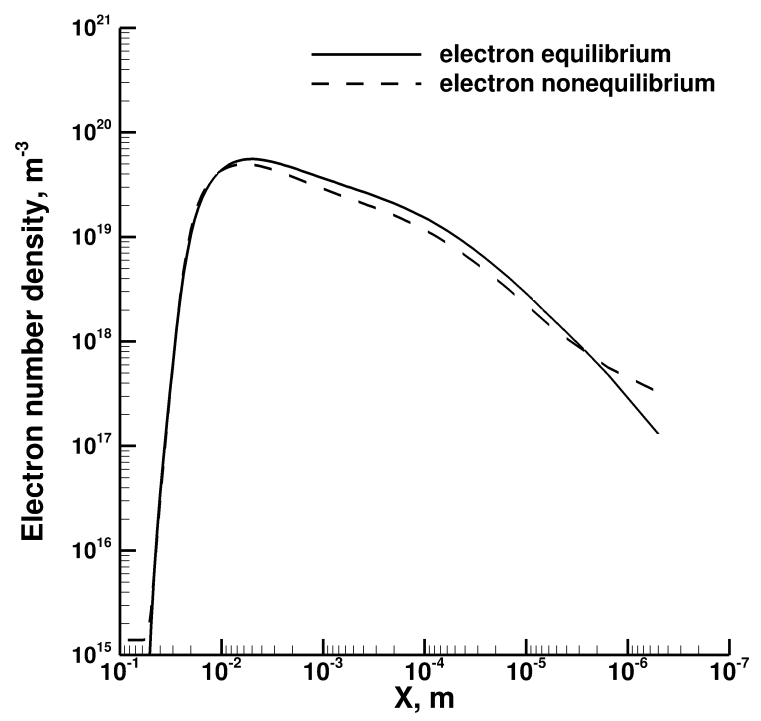

(b) $81 \mathrm{~km}$ flight condition.

Figure 10: Electron number density computed along the stagnation streamline for Stardust at both flight conditions. 
Again, the level of surface heat flux did not change appreciably at either flight condition when the additional electron translational energy equation was included in the simulations. Figures 11(a) and 11(b) show the radiation spectra computed using NEQAIR over the entire range of the Echelle instrument, along with the data from that instrument, for the $71 \mathrm{~km}$ and $81 \mathrm{~km}$ flight conditions. Note that the underlying continuum signal from the heated surface of the Stardust sample return capsule is not included in the computed spectra.

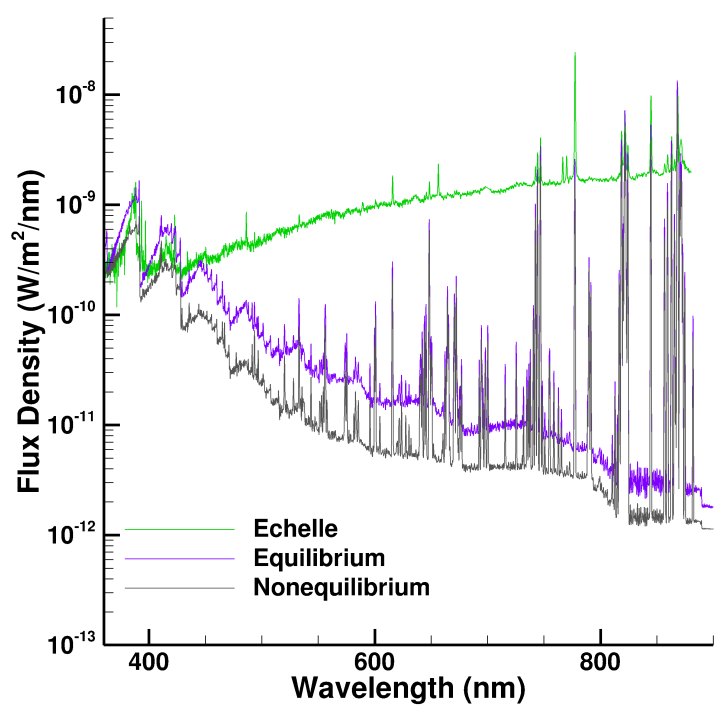

(a) $71 \mathrm{~km}$ flight condition.

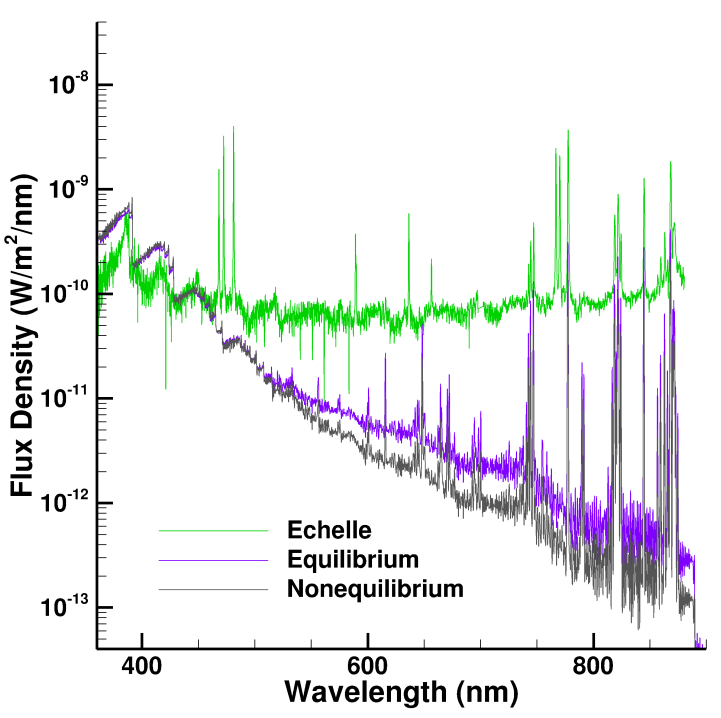

(b) $81 \mathrm{~km}$ flight condition.

Figure 11: Full radiation spectra for Stardust at both flight conditions.

To better assess the differences between the predicted spectra, narrower bandwidth ranges are examined. In Figure 12, spectra are shown in the range of 370-420 nm at both flight conditions. In this region, there is a strong cyanide $(\mathrm{CN})$ signal that partially overwhelms some of the emission at $391.4 \mathrm{~nm}$ attributed to the bandhead of the $\mathrm{N}_{2}^{+}$molecular system. At the $81 \mathrm{~km}$ flight condition, both the electron equilibrium and nonequilibrium results slightly over-predict the $\mathrm{N}_{2}^{+}$bandhead, however they are in good agreement with each other. At the $71 \mathrm{~km}$ flight condition, the electron nonequilibrium result is in slightly better agreement with the data from the Echelle instrument. Figure 13 shows the number density of $\mathrm{N}_{2}^{+}$along the stagnation streamline from the simulations at this flight condition. The predictions from the electron nonequilibrium simulation are almost an order of magnitude lower than those from the equilibrium simulation in the high density region located around $0.01 \mathrm{~m}$. Figure 9(a) shows a large decrease in the predicted translational temperature at this location when the electron nonequilibrium model is used. Since the associative ionization rate for the $\mathrm{N}+\mathrm{N} \leftrightarrow \mathrm{N}_{2}^{+}+$e reaction is completely determined by the translational temperature (see Table 3), the decrease in temperature leads to a decrease in the production of $\mathrm{N}_{2}^{+}$and a reduction in the radiative emission from the $\mathrm{N}_{2}^{+}$molecular system. Since the maximum degree of ionization in the flow field is approximately $26 \%$ at the $71 \mathrm{~km}$ flight condition and only $2 \%$ at the $81 \mathrm{~km}$ flight condition, electrons account for a much larger portion of the flow field composition at the lower altitude condition. This means that the choice of method used to model the electron translational mode may have a more pronounced effect on the prediction of certain flow field properties and radiation signals at the $71 \mathrm{~km}$ flight condition. This appears to be the case with the prediction of radiative emission from the $\mathrm{N}_{2}^{+}$molecular system.

In Figure 14, spectra are shown in the range of 810-880 nm that contain several lines of atomic nitrogen and oxygen. Figure 15 shows computed and measured spectra in the 740-780 $\mathrm{nm}$ range that also contain atomic oxygen and nitrogen lines, as well as two potassium lines. In both ranges, there is only a small difference between the predictions of the electron equilibrium and nonequilibrium cases at the $71 \mathrm{~km}$ flight condition, and the results from the electron equilibrium calculation are in slightly better agreement with the Echelle data. At the $81 \mathrm{~km}$ flight condition, modeling electron nonequilibrium reduces the agreement with 
the measured spectra more significantly than at the higher density flight condition. The predicted number densities of atomic oxygen and nitrogen are very similar between the two simulations, so this result is likely due to the slight reduction in electron number density with the addition of electron nonequilibrium (see Figure 10(b)) over the majority of the shock layer at this flight condition.

\section{IV.C. Chemistry Modeling}

The $71 \mathrm{~km}$ RAM-C II flight condition and the $81 \mathrm{~km}$ Stardust flight condition are chosen as test cases to examine the importance of the selection of the controlling temperature. At higher altitudes, a larger portion of the shock layer is in thermal nonequilibrium and the chemical state of the shock layer should be further from equilibrium. For these reasons, it is expected that the choice of controlling temperature will play a more important role in determining the flow field character in these cases than in the lower altitude cases.

Of all of the combinations of modified temperature parameters listed in Table 4, only the use of the combinations involving the associative ionization and dissociative recombination reaction mechanisms resulted in any appreciable change in the flow field parameters of interest. There are two possible reasons for this result. In some reactions, for example electron impact ionization, the controlling temperature is already set by the electron translational or vibrational/electronic temperatures of the flow field. Since the coupling between the vibrational/electronic and the electron translational modes is very strong, these two modes are nearly in equilibrium. Thus, the electron impact ionization and electron impact dissociation rate does not change appreciably from the baseline value when the parameters specified in Table 4 are used. Additionally, for some reactions, the lack of response to the modified parameters may indicate that a particular reaction mechanism does not play a large role in determining the flow field character at the conditions examined in this study.

Three different combinations for the temperature parameters a, b and c in Equation 6 were investigated with respect to the associative ionization reactions. This reaction mechanism is given below for air species.

$$
\begin{aligned}
N+O & \leftrightarrow O^{+}+e \\
N+N & \leftrightarrow N_{2}^{+}+e \\
O+O & \leftrightarrow O_{2}^{+}+e
\end{aligned}
$$

The reaction cross sections for the $\mathrm{N}+\mathrm{O} \leftrightarrow \mathrm{NO}^{+}+$e reaction of this type are a strong function of the electronic states of the colliding atoms. ${ }^{23,24}$ It stands to reason that similar trends exist for the other two associative ionization reactions, and this approach is adopted here. The baseline parameters specify a controlling temperature determined entirely by the translational-rotational temperature of the flow, $a=1$, $\mathrm{b}=\mathrm{c}=0$, which gives no weight to the value of the electronic temperature of the flow field. The temperature parameters are denoted by bracket notation, for example $\left(\begin{array}{lll}1 & 0 & 0\end{array}\right)$, in the Figures that follow. Two different parameter combinations are tested, that allow the electronic temperature (which in these simulations is equal to the vibrational temperature but realistically should be closer to the electron translational temperature) to determine the rate of reaction with equal weight. These cases are denoted $\left(\begin{array}{lll}0.5 & 0.5 & 0\end{array}\right)$ and $\left(\begin{array}{lll}0.5 & 0 & 0.5\end{array}\right)$. Additionally, a simulation is conducted in which the rate of reaction is governed solely by the electron translational temperature, denoted $\left(\begin{array}{lll}0 & 0 & 1\end{array}\right)$.

With respect to the reaction proceeding in the opposite direction, the dissociative recombination reaction, there is inconclusive information regarding the dependence of the reaction cross sections on the vibrational or electronic state of the molecules. ${ }^{25-30}$ However, it is reasonable to assume that while there will be some dependence on the internal energy of the molecule, there will also be a dependence on the translational energy of the molecule. Thus, one simulation is run with the parameters $\left(\begin{array}{lll}0.5 & 0 & 0.5\end{array}\right)$ for the dissociative recombination reactions to assess any changes in the flow field structure. 


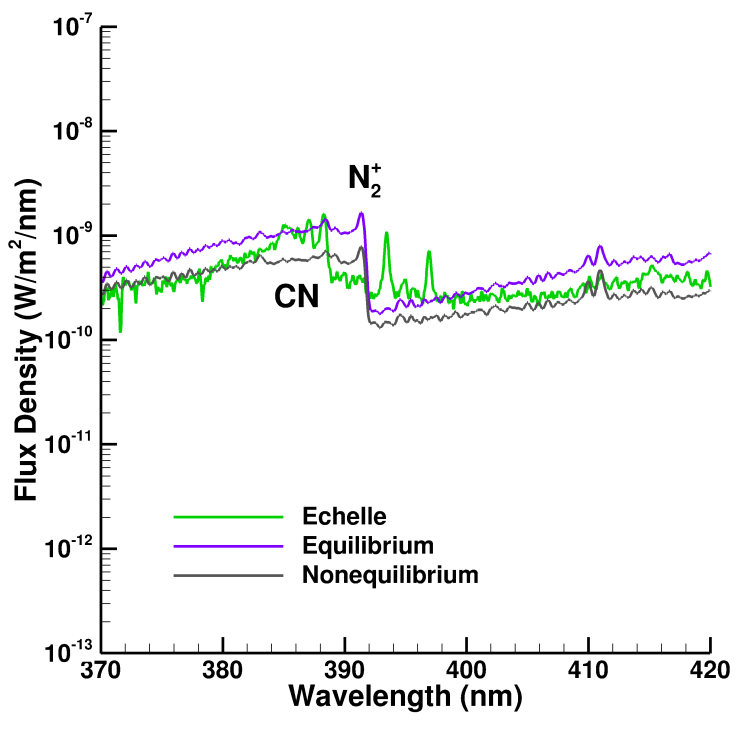

(a) $71 \mathrm{~km}$ flight condition.

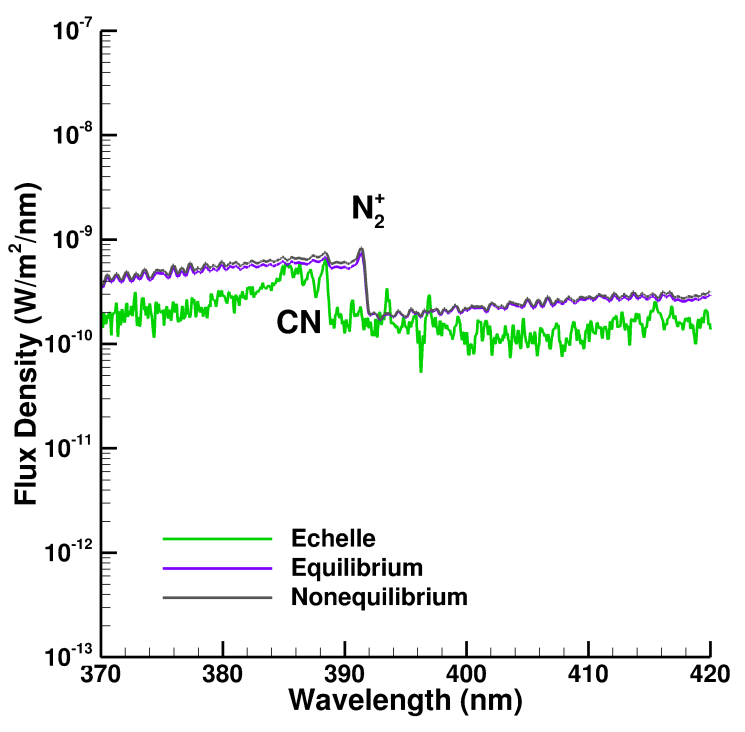

(b) $81 \mathrm{~km}$ flight condition.

Figure 12: Comparisons of measured and computed spectra focusing on air molecular bands.

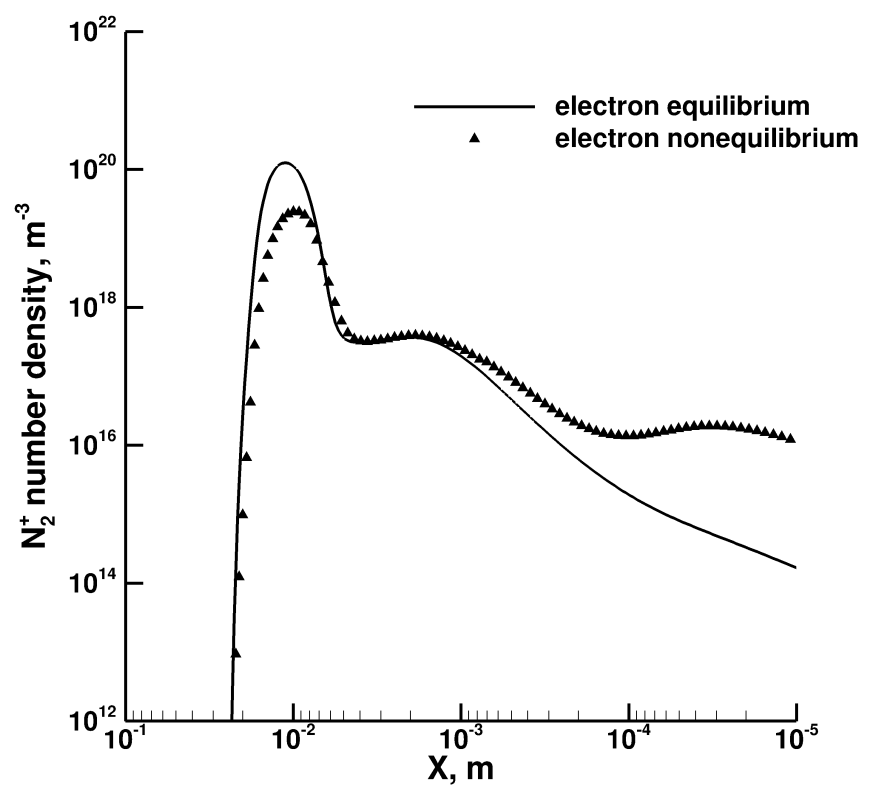

Figure 13: Number density of $\mathrm{N}_{2}^{+}$along the stagnation streamline for Stardust at an altitude of $71 \mathrm{~km}$. 


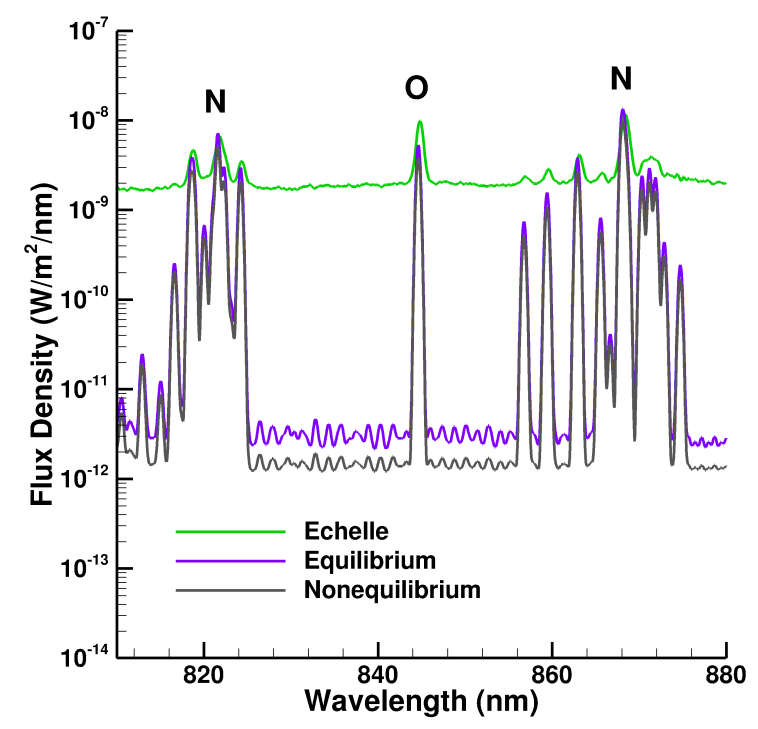

(a) $71 \mathrm{~km}$ flight condition.

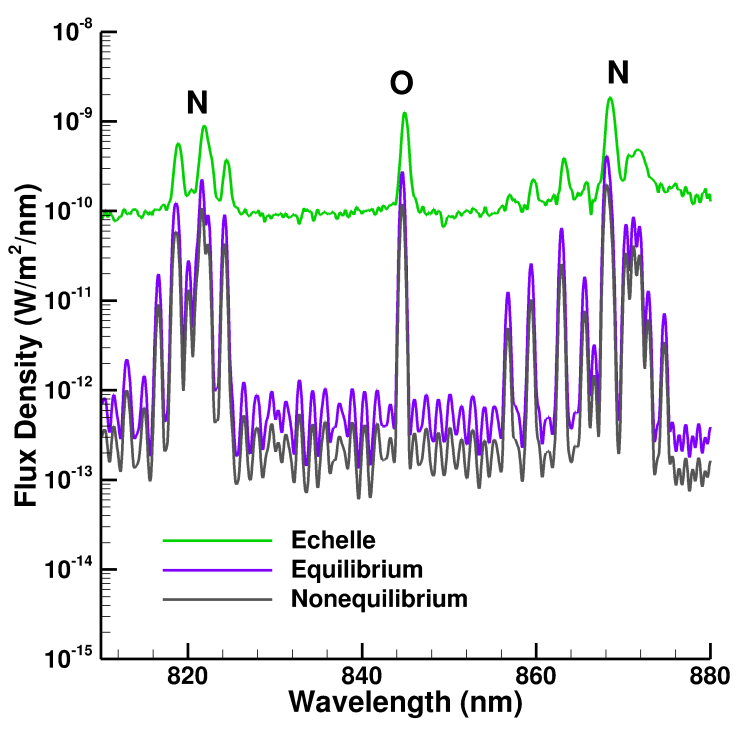

(b) $81 \mathrm{~km}$ flight condition.

Figure 14: Comparisons of measured and computed spectra focusing on air atomic lines.

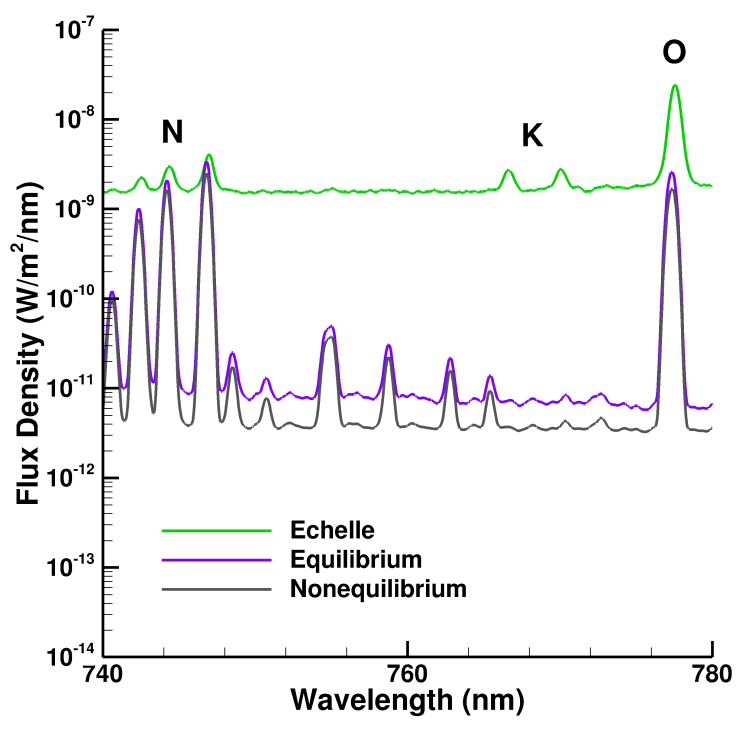

(a) $71 \mathrm{~km}$ flight condition.

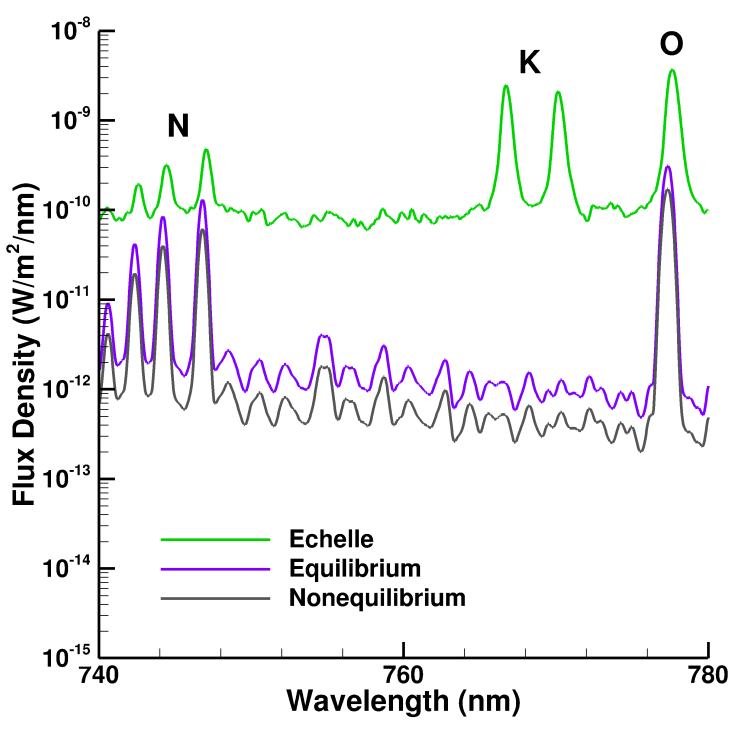

(b) $81 \mathrm{~km}$ flight condition.

Figure 15: Comparisons of measured and computed spectra focusing on air and potassium atomic lines. 
The effect of these modifications on the predicted electron temperature and number density for the RAMC II, $71 \mathrm{~km}$ flight condition is shown in Figures 16(a) and 16(b). Similar plots for the Stardust $81 \mathrm{~km}$ flight condition are shown in Figures 17(a) and 17(b). The results for the simulation with associative ionization parameters of $\left(\begin{array}{lll}0.5 & 0 & 0.5\end{array}\right)$ are omitted from these Figures, since they were nearly identical to those obtained with the parameters of $(0.50 .50)$. This is not surprising, as the coupling between the vibrational and electron translational modes is very strong, and results in those two temperatures being nearly equal over the majority of the high density region of the flow.

For both combinations of modified associative ionization parameters and both flight conditions, the predicted electron density is lower than the baseline value over the entire shock layer. In these cases, the predicted electron translational temperature is either similar to, or lower than, the baseline value. Since the baseline parameters of $\left(\begin{array}{lll}1 & 0 & 0\end{array}\right)$ for the associative ionization reaction result in the determination of the reaction rate by the translational temperature only, it makes sense that the reaction rate will be reduced when it is determined partially by the lower vibrational-electronic or electron translational temperatures. Of course, the AI $\left(\begin{array}{lll}0 & 0 & 1\end{array}\right)$ case is the most extreme, as none of the translational energy participates in determining the reaction rate. This case results in the lowest predicted electron densities. Conversely, when the translational temperature participates in the determination of the reaction rate for the dissociative recombination reactions, the computed rates are higher than those from the baseline simulations. Counterintuitively, this results in a slight increase in the predicted electron number density throughout the shock layer for both flight conditions. This may be the result of interplay between the associative ionization and electron impact ionization reaction mechanisms. While these results do not point conclusively to "correct" temperature parameters for use with thermal nonequilibrium CFD simulations, they identify a set of reaction mechanisms for which further investigation of the modeling procedures is warranted when detailed predictions of electron properties are desired.

\section{Conclusions}

A separate electron translational energy conservation equation was included in CFD simulations of the flow around the RAM-C II reentry vehicle and the Stardust reentry capsule at different altitudes. The results of the simulations were compared to results from the baseline simulations in which the electron translational energy mode was coupled to the vibrational-electronic energy mode.

In all simulations, the electron translational temperature remained in equilibrium with the vibrationalelectronic temperature over almost the entire shock layer, except for in the low density region upstream of the shock where the electron density is very low.

At both flight conditions simulated for the RAM-C II vehicle, the separation of the electron translational mode from the vibrational-electronic mode resulted in a significant decrease in the predicted electron number density in the shock layer, by as much as an order of magnitude at the $71 \mathrm{~km}$ flight condition. Additionally, the predicted translational temperature increased, and the vibrational-electronic temperature decreased in the simulation that included the electron translational energy equation. In general, inclusion of a separate electron translational mode resulted in better agreement of the simulation results with the available experimental data from the RAM-C II flight.

For the Stardust simulations, the differences in flow field predictions between the electron equilibrium and nonequilibrium cases were generally less significant, although at both flight conditions, the predicted electron number density in the boundary layer increased by a factor of more than two when the electron nonequilibrium model was used. When the separate electron translational energy mode was added to the simulation, there was a slight decrease in the level of agreement between the computed and measured radiation spectra in the region of the atomic air lines. At the $71 \mathrm{~km}$ flight condition, there was an improvement in the prediction of the $N_{2}^{+}$bandhead feature when the electron translational energy mode was modeled.

For both sets of simulations, the level of disagreement between the electron equilibrium and nonequilibrium results did not consistently correlate with differences in the free stream Knudsen number. At the $61 \mathrm{~km}$ RAM-C II flight condition, there was a significant decrease in the maximum predicted electron number density in the flow field when the electron nonequilibrium model was used, and the results obtained using that model provided the best agreement with the measured flight data. This could be because a larger portion of the electrons are created in electron impact ionization events at this altitude, and that reaction is very sensitive to the modeling of electron translational temperature. At the $71 \mathrm{~km}$ Stardust flight condition, there was a significant decrease in the predicted radiative emission from the $\mathrm{N}_{2}^{+}$molecular system when the 


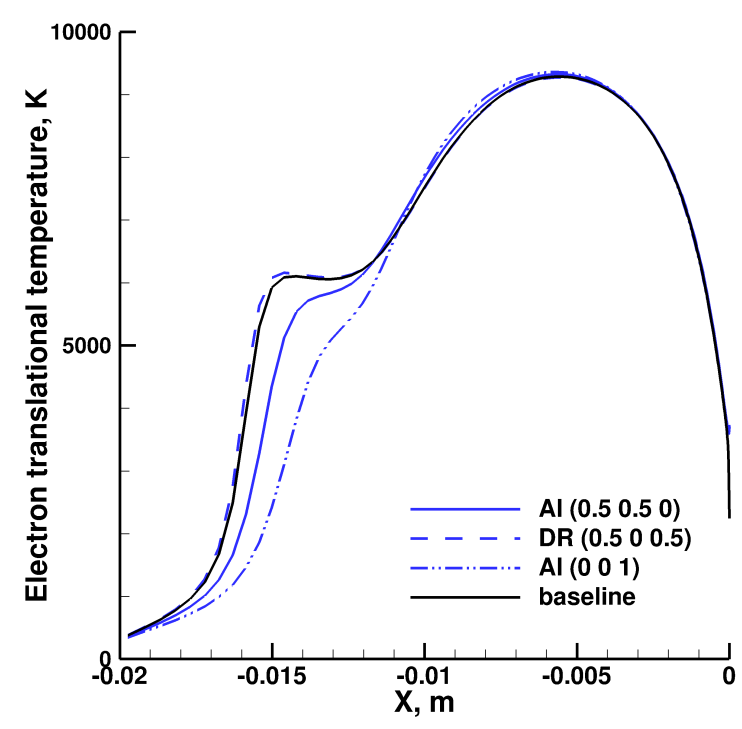

(a) Electron translational temperature.

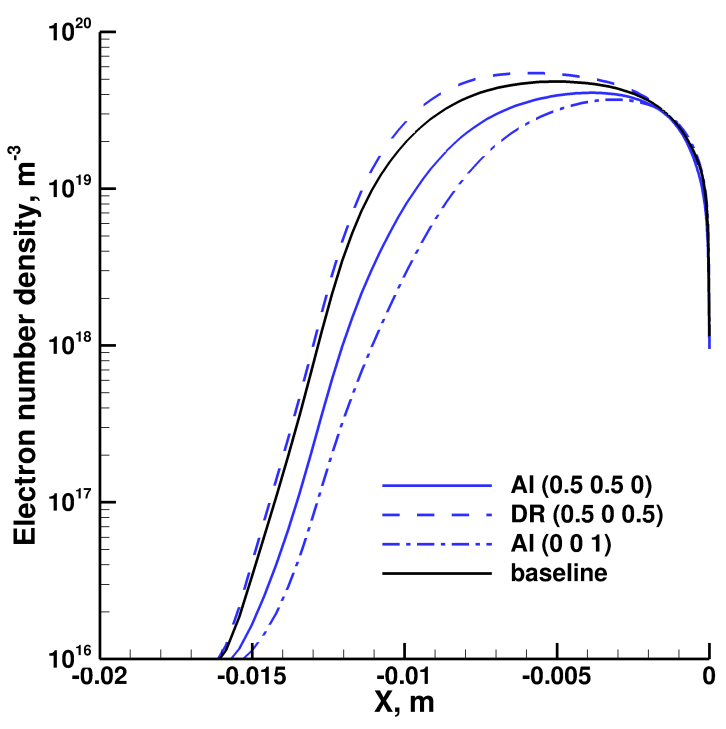

(b) Electron number density.

Figure 16: Effect of the modified reaction rate parameters on electron properties for the RAM-C II, $71 \mathrm{~km}$ flight condition.

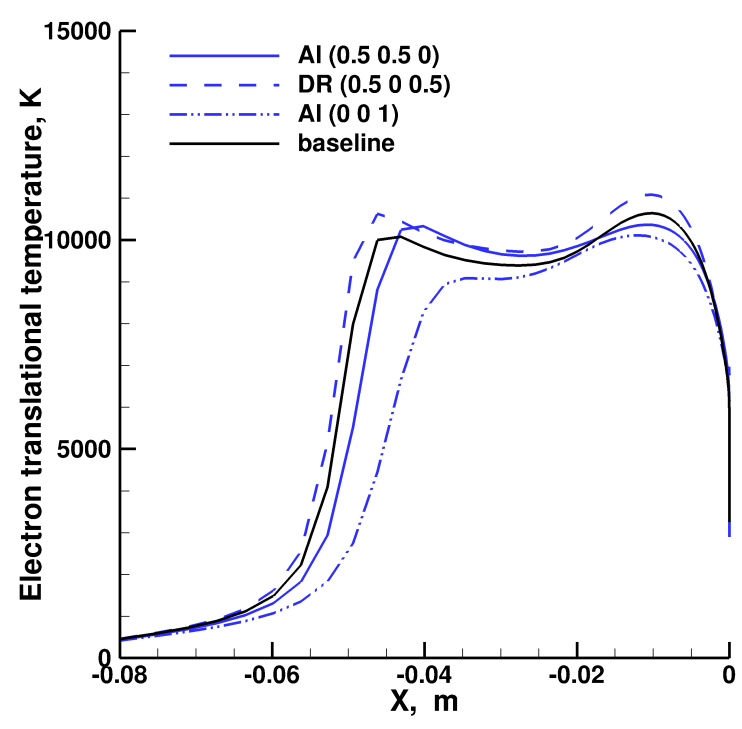

(a) Electron translational temperature.

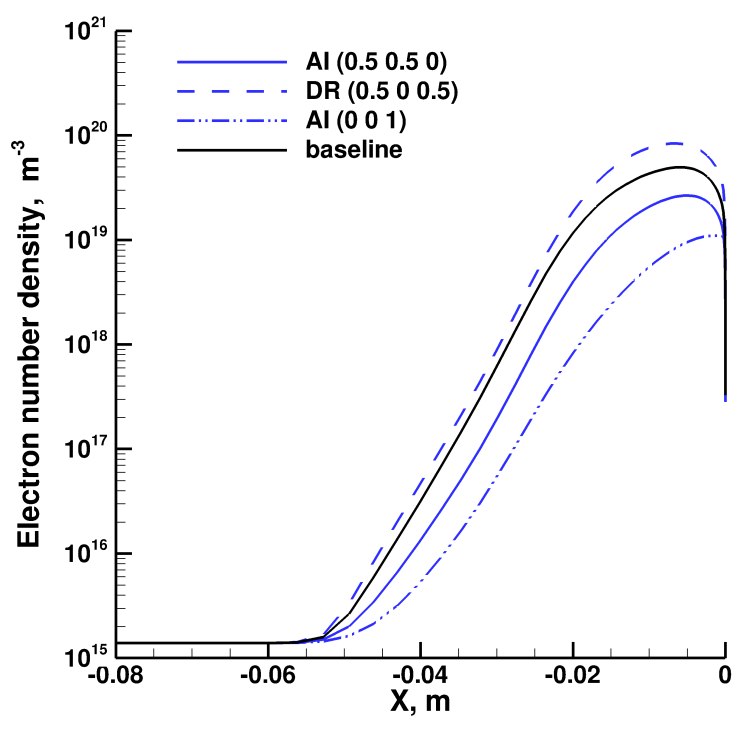

(b) Electron number density.

Figure 17: Effect of the modified reaction rate parameters on electron properties for the Stardust, $81 \mathrm{~km}$ flight condition. 
nonequilibrium electron model was used. This was the result of a large change in the translational temperature in the shock layer at this altitude, which in turn resulted in a decrease in the rate of the associative ionization reaction that leads to the production of $\mathrm{N}_{2}^{+}$and a corresponding decrease in the predicted $\mathrm{N}_{2}^{+}$ density in the shock layer. This effect was not observed in the results of the simulations conducted at the $81 \mathrm{~km}$ altitude flight condition, likely because the degree of ionization is an order of magnitude lower in that case, rendering some of the flow field properties less sensitive to the choice of electron temperature model. Additional investigation into the cause of these phenomena is necessary.

The sensitivity of the different chemical reaction mechanisms in air to the use of the electron translational temperature for determining the controlling temperature was investigated. The associative ionization and dissociative recombination reaction mechanisms were sensitive to the use of the electronic or electron translational temperature in the definitions of the controlling temperature. At the higher altitude flight conditions of both vehicles, variations in electron number density of up to an order of magnitude in some regions of the flow field were predicted. This may be significant for flow field simulations where the prediction of electron properties is the primary concern, and further research regarding the modeling of these reaction mechanisms may be warranted in these cases. Additionally, while the method for evaluation of the rates of these reactions were varied in this study, the way in which energy was added or removed from the various energy modes as a result of the reactions was not examined. This is also an area where further research is required.

\section{Acknowledgments}

This work was funded in part by the Air Force STTR Phase I Contract FA9550-10-C-0089. E. Farbar would also like to thank Dr. Jon Burt for useful discussions regarding the LeMANS code.

\section{References}

\footnotetext{
${ }^{1}$ Linwood-Jones, W. and Cross, A. E., "Electrostatic Probe Measurements of Plasma Parameters for Two Reentry Flight Experiments at 25000 Feet Per Second," Tech. Rep. NASA Technical Note D-6617, Langley Research Center, 1972.

${ }^{2}$ Grantham, W. L., "Flight Results of a 25000 foot per second Reentry Experiment Using Microwave Reflectometers to Measure Plasma Density and Standoff Distance," Tech. Rep. NASA Technical Note D-6062, Langley Research Center, 1970.

${ }^{3}$ Candler, G. V. and MacCormack, R. W., "Computation of Weakly Ionized Hypersonic Flows in Thermochemical Nonequilibrium," Journal of Thermophysics and Heat Transfer, Vol. 5, No. 3, 1991, pp. 266-273.

${ }^{4}$ Josyula, E. and Bailey, W. F., "Governing Equations for Weakly Ionized Plasma Flowfields of Aerospace Vehicles," Journal of Spacecraft and Rockets, Vol. 40, No. 6, 2003, pp. 845-857.

${ }^{5}$ Scalabrin, L. C. and Boyd, I. D., "Numerical Simulation of Weakly Ionized Hypersonic Flow for Reentry Configurations," AIAA Paper 2006-3773, presented at the 9th AIAA/ASME Joint Thermophysics and Heat Transfer Conference, San Francisco, CA, June 2006.

${ }^{6}$ Bird, G., "Computation of Electron Density in High Altitude Re-Entry Flows," AIAA Paper 89-1882, presented at the 20th Fluid Dynamics, Plasma Dynamics and Lasers Conference, Buffalo, NY, June 1989.

${ }^{7}$ Boyd, I. D., "Modeling of Associative Ionization Reactions in Hypersonic Rarefied Flows," Physics of Fluids, Vol. 19, 2007, pp. 096102.

${ }^{8}$ Jenniskens, P., "Observations of the STARDUST Sample Return Capsule Entry With a Slit-less Echelle Spectrograph," AIAA Paper 2008-1210, presented at the 46th AIAA Aerospace Sciences Meeting and Exhibit, Reno, NV, Jan. 2008.

${ }^{9}$ Boyd, I. D., Trumble, K., and Wright, M. J., "Modeling of Stardust Entry at High Altitude, Part 1: Flowfield Analysis," Journal of Spacecraft and Rockets, Vol. 47, No. 5, 2010, pp. 708-717.

${ }^{10}$ Olynick, D., Chen, Y.-L., and Tauber, M. E., "Aerothermodynamics of the Stardust Return Capsule," Journal of Spacecraft and Rockets, Vol. 36, No. 3, 1999, pp. 442-462.

${ }^{11}$ Ozawa, T., Zhong, J., Levin, D. A., and Boger, D., "Modeling of the Stardust Reentry Flows with Ionization in DSMC." AIAA Paper 2007-0611, presented at the 45th AIAA Aerospace Sciences Meeting and Exhibit, Reno, NV, Jan. 2007.

${ }^{12}$ Boyd, I. D. and Jenniskens, P., "Modeling of Stardust Entry at High Altitude, Part 2: Radiation Analysis," Journal of Spacecraft and Rockets, Vol. 47, No. 6, 2010, pp. 901-909.

${ }^{13}$ Martin, A. and Boyd, I. D., "CFD Implementation of a Novel Carbon-Phenolic-in-Air Chemistry Model for Atmospheric Re-entry," AIAA-2011-143, presented at the 49th AIAA Aerospace Sciences Meeting and Exhibit, Orlando, FL, Jan. 2011.

${ }^{14}$ Kim, M., Gülhan, A., and Boyd, I. D., "Modeling of Electron Temperature in Hypersonic Flows," AIAA-2011-1028, presented at the 49th AIAA Aerospace Sciences Meeting and Exhibit, Orlando, FL, Jan. 2011.

${ }^{15}$ Wilmoth, R. G., Mitcheltree, R. A., and Moss, J. N., "Low-Density Aerodynamics of the Stardust Sample Return Capsule," Journal of Spacecraft and Rockets, Vol. 36, No. 3, 1999, pp. 436-441.

${ }^{16}$ Scalabrin, L. C., Numerical Simulation of Weakly Ionized Hypersonic Flow Over Reentry Capsules, Ph.D. thesis, The University of Michigan, 2007.

${ }^{17}$ Park, C., "Review of Chemical-Kinetic Problems of Future NASA Missions, I: Earth Entries," Journal of Thermophysics and Heat Transfer, Vol. 7, No. 3, 1993, pp. 385-398.
} 
${ }^{18}$ Park, C., Nonequilibrium Hypersonic Aerothermodynamics, John Wiley and Sons, 1990.

${ }^{19}$ Lee, J., "Basic Governing Equations for the Flight Regimes of Aeroassisted Orbital Transfer Vehicles," Thermal Design of Aeroassisted Orbital Transfer Vehicles, edited by H. F. Nelson, Vol. 96 of Progress in Astronautics and Aeronautics, AIAA, New York, 1984, pp. 3-53.

${ }^{20}$ Farbar, E. D. and Boyd, I. D., "Simulations of Reactions Involving Charged Particles in Hypersonic Rarefied Flows," AIAA Paper 2009-0267, presented at the 47th AIAA Aerospace Sciences Meeting, Orlando, FL, Jan. 2009.

${ }^{21} \mathrm{Li}, \mathrm{Z}$., Ozawa, T., Sohn, I., and Levin, D. A., "Challenges of Modeling of Electronic State Specific Processes for Hypersonic Reentry Flows in DSMC," AIAA-2011-0536, presented at the 49th AIAA Aerospace Sciences Meeting and Exhibit, Orlando, FL, Jan. 2011.

${ }^{22}$ Whiting, E., Park, C., Liu, Y., Arnold, J. O., and Paterson, J. A., "NEQAIR96, Nonequilibrium and Equilibrium Radiative Transport and Spectra Program: User's Manual," Tech. Rep. NASA RP-1389, 1996.

${ }^{23}$ Padellec, A. L., "Partial Near Threshold Cross Sections for the Associative Ionization to form $\mathrm{CO}^{+}, \mathrm{NO}^{+}$and $\mathrm{O}_{2}^{+}$," Physica Scripta, Vol. 71, 2005, pp. 621-626.

${ }^{24}$ Ringer, G. and Gentry, W. R., "A Merged Molecular Beam Study of the Endoergic Associative Ionization Reaction $\mathrm{N}\left({ }^{2} \mathrm{D}\right)+\mathrm{O}\left({ }^{3} \mathrm{P}\right) \rightarrow \mathrm{NO}^{+}+\mathrm{e}^{-}, "$ Journal of Chemical Physics, Vol. 71, No. 4, 1979, pp. 1902-1909.

${ }^{25}$ Sun, H. and Nakamura, H., "Theoretical Study of the Dissociative Recombination of $\mathrm{NO}^{+}$With Slow Electrons," Journal of Chemical Physics, Vol. 93, No. 9, 1990, pp. 6491-6501.

${ }^{26}$ Vejby-Christensen, L., Kella, D., Pedersen, H. B., and Andersen, L. H., "Dissociative Recombination of NO ${ }^{+}$," Physical Review A, Vol. 57, No. 5, 1998, pp. 3627-3634.

${ }^{27}$ Davidson, D. F. and Hobson, R. M., "The Shock Tube Determination of the Dissociative Recombination Rate of $\mathrm{NO}^{+}, "$ Journal of Physics B: Atomic and Molecular Physics, Vol. 20, 1987, pp. 5753-5756.

${ }^{28}$ Mostefaoui, T., Laube, S., Gautier, G., Rebrion-Rowe, C., Rowe, B. R., and Mitchell, J. B. A., "The Dissociative Recombination of $\mathrm{NO}^{+}$: The Influence of the Vibrational Excitation State," Journal of Physics B: Atomic, Molecular and Optical Physics, Vol. 32, 1999, pp. 5247-5256.

${ }^{29}$ Peterson, J. R., Padellec, A. L., Danared, H., Dunn, G. H., Larsson, M., Larson, A., Peverall, R., Stromholm, C., Rosen, S., af Ugglas, M., and van der Zande, W. J., "Dissociative Recombination and Excitation of $\mathrm{N}_{2}^{+}$: Cross Sections and Product Branching Ratios," Journal of Chemical Physics, Vol. 108, No. 5, 1998, pp. 1978-1988.

${ }^{30}$ Peverall, R., Rosen, S., Peterson, J. R., Larsson, M., Al-Khalili, A., Vikor, L., Semaniak, J., Bobbenkamp, R., Padellec, A. L., Maurellis, A., and van der Zande, W. J., "Dissociative Recombination and Excitation of $\mathrm{O}_{2}^{+}$: Cross Sections Product Yields and Implications for Studies of Ionospheric Airglows," Journal of Chemical Physics, Vol. 114, No. 15, 2001, pp. 66796689 . 